\title{
A Short Review on Fluoride Laser Crystals Grown by Czochralski Method at IPEN
}

\author{
S.L. BALDOCHI* AND I.M. RANIERI \\ Instituto de Pesquisas Energéticas e Nucleares, IPEN - CNEN/SP, 05508-000 São Paulo, SP, Brazil
}

\begin{abstract}
In this article there are presented the developments on the crystal growth by the Czochralski method of fluoride laser materials at the Center for Lasers and Applications from Institute of Nuclear and Energy Research, IPEN, Brazil. A brief report of the Czochralski furnace preparation for fluorides growth regarding to its construction materials, influence of the heating assemblies in the thermal profiles and the benefits of using a suitable atmosphere is provided. Moreover, to demonstrate the importance of this technique to the advances on laser systems over the last years there are described the specific growth conditions established to obtain fluoride crystals with suitable properties for practical application as laser hosts. $\mathrm{LiREF}_{4}(\mathrm{RE}=$ rare earth) scheelite crystals have been studied to compare $\mathrm{LiYF}_{4}$ (YLF) with its isomorphs, including solid solutions of the type-LiY ${ }_{1-x} \operatorname{Ln}_{x} \mathrm{~F}_{4}(\mathrm{Ln}=\mathrm{Gd}$ or $\mathrm{Lu})$ and $\mathrm{LiGd}_{1-x} \mathrm{Lu}_{x} \mathrm{~F}_{4}$, relating to their optical quality, spectroscopic and laser properties. Some results regarding the development of new laser hosts of these materials doped with Nd, Er, Pr and co-doped Yb, Nd and Tm are also presented. The growth particularities of transition metals doped fluoride crystals such as BaLiF $3: \mathrm{TM}(\mathrm{TM}=\mathrm{Ni}$ and $\mathrm{Co}$ ) and $\mathrm{LiSrAlF}_{6}: \mathrm{Cr}$ are also reported.
\end{abstract}

DOI: $10.12693 /$ APhysPolA.124.286

PACS: 81.10.Fq, 42.70.-a, 42.70.Hj

\section{Introduction}

For any application demanding the development of one crystal class, it is first fundamental to identify the appropriate means of growing and fabricating the desired crystals. From this point of view the Czochralski (CZ) method fitted very well in the past 50 years to the development of bulk laser crystals. Hurle [1] mentioned, in the earlier development of the semiconductor electronics, that the first important use for $\mathrm{CZ}$ method was the development of silicon and germanium and the next major application was established after the discovery of the solid state lasers. Pioneering work on laser materials on the sixties [2] showed that the technique was capable of yielding crystals of higher optical perfection than others used at the time, additionally, the method provided larger crystals size and faster growth rates. In fact, the $\mathrm{CZ}$ growth process is until nowadays the most commonly used process for the growth of laser materials (the Bridgman method is also used but in a lower scale, as well other techniques); and it was already employed over a wider span of materials and melting points than any other melt growth method, ranging from compounds such as fluorides, molybdates, tantalates and garnets, to single oxides such as sapphire and yttria [3]. Evidently, for any of these material's family, modifications on specific features or improvement on particular growth conditions were necessary to overcome difficulties or to improve quality of the obtained crystals. In this paper we review, in particular, the development of $\mathrm{CZ}$ growth of fluoride laser crystals.

\footnotetext{
*corresponding author; e-mail: baldochi@ipen.br
}

Fluoride crystals have long presented a challenge for chemists and physicists, because their preparation often requires very specific procedures. Their synthesis usually requires the use of toxic and/or corrosive materials, procedures demanding suitable equipment, and safety operational norms. Additionally, most of the fluoride compounds are moisture sensitive. As a result, a dry working environment is always needed, and a preliminary treatment or synthesis of the raw material to be used for the crystal preparation is the first step in the growth of fluoride crystals [4]. Concerning crystalline laser host, in a general way, it must possess properties that are compatible with the normal operating conditions of the laser. That is, the crystal must have good optical, mechanical and thermal properties to withstand the operating conditions of practical lasers. Desirable properties include hardness, chemical inertness, absence of internal strain and refractive index variations, resistance to radiation induced color center, and ease to fabrication [5].

In this year dedicated to Prof. Jan Czochralski, we show the importance of the $\mathrm{CZ}$ technique for fluoride laser crystals discussing the work performed in the last 25 years at the Crystal Growth Laboratory of the Center for Lasers and Applications - IPEN, Brazil. The discussion of specific growth conditions established to obtain fluoride crystals with suitable quality for its application as laser hosts, the most important dopant active ions and their influence in the crystal growth process, and the properties of the laser systems of this class of optical materials is presented.

\section{CZ furnace for fluoride crystals growth}

It is well known that the $\mathrm{CZ}$ method is a typical growth process from the melt. The most of the fluorides melts below $1000{ }^{\circ} \mathrm{C}$, which makes the growth apparatus rel- 
atively simple compared to the growth of oxide crystals, for example. Resistive furnaces are often used in research laboratories, because they are cheaper and easier to build. Nevertheless, inductive furnaces can also be adopted once the appropriate thermal configuration is designed. For fluorides the control of the furnace atmosphere and the use of materials (growth chamber and components) resistant to HF corrosion are two fundamental points for preparation of high quality crystals. The growth of fluoride crystals by the $\mathrm{CZ}$ method was already performed in both: vacuum-tight systems and open systems with gas flow. However, it is important to observe that in an open system a low level of oxygen contamination will always be present, because of the residual oxygen in the streaming gas. In a vacuum-tight system this problem is solved, being the appropriate choice for high quality crystals [4].

It is important to note that fluoride compounds react easily with oxygen and moisture. When oxygen or moisture is present during the growth process, there is the formation of oxygen complexes in the crystals. In general, they are usually accompanied by other oxygen complexes, such as, $\mathrm{O}^{2-}+$ vacancy, domains with fluorine-hydroxyl substitutions $\left(\mathrm{RE}(\mathrm{OH})_{3}, \mathrm{Me}(\mathrm{OH})_{2}(\mathrm{Me}=\mathrm{Mg}, \mathrm{Mn}\right.$ or $\mathrm{Ti})$ complexes), or $\mathrm{HCO}^{-}$molecules [6]. The optical properties of the crystals are greatly influenced by the presence of these complexes, as they are responsible for losses in the laser media. As it will be discussed further below, the use of reactive atmospheres, such as $\mathrm{HF}$ or $\mathrm{CF}_{4}$, during the synthesis of the raw material or the growth process prevents the fluoride degradation $[7,8]$, but the reaction chamber (or furnace chamber) must be resistant to such atmospheres.

In the early years of crystal laser research many laboratories had to adapt or construct their CZ furnaces for fluoride growth, however, today there are some commercial companies providing the correct instrumentation for operation under controlled and corrosive atmospheres. As an example of the evolution of such systems in our laboratories, Fig. 1 shows two different $\mathrm{CZ}$ furnaces: (A) is a home-made $\mathrm{CZ}$ furnace constructed in the eighties, for the crystal growth of alkaline halide crystals, mainly LiF for color center laser studies. Later the same furnace was modified and also used to the growth of rare earth doped- $\mathrm{LiYF}_{4}$ or $-\mathrm{BaY}_{2} \mathrm{~F}_{8}$ and transition metal doped$-\mathrm{BaLiF}_{3}(\mathrm{Ni}, \mathrm{Co}, \mathrm{Pb})$; (B) shows a system acquired from a commercial supplier, with automatic diameter control, and modified to the growth of large fluoride single crystals (for preparation of laser rods for solid state laser research), used to the growth of $\mathrm{Li}(\mathrm{RE})_{x}(\mathrm{RE})_{(1-x)} \mathrm{F}_{4}$ (doped or mixed) crystals (where $\mathrm{RE}=\mathrm{Y}$ or rare earth ions) and $\mathrm{LiSrAlF}_{6}: \mathrm{Cr}(\mathrm{LiSAF}: \mathrm{Cr})$ and $\mathrm{LiCaAlF}_{6}: \mathrm{Cr}(\mathrm{Li}-$ $\mathrm{CAF}: \mathrm{Cr})$ crystals. This furnace was originally designed for oxides growth and the hot region configuration was specially modified for the growth of fluorides. Figure $1 \mathrm{C}$ and $\mathrm{D}$ shows a view of the hot region during a growth process of RE-doped fluoride crystal and a detail of the components of the system, respectively.

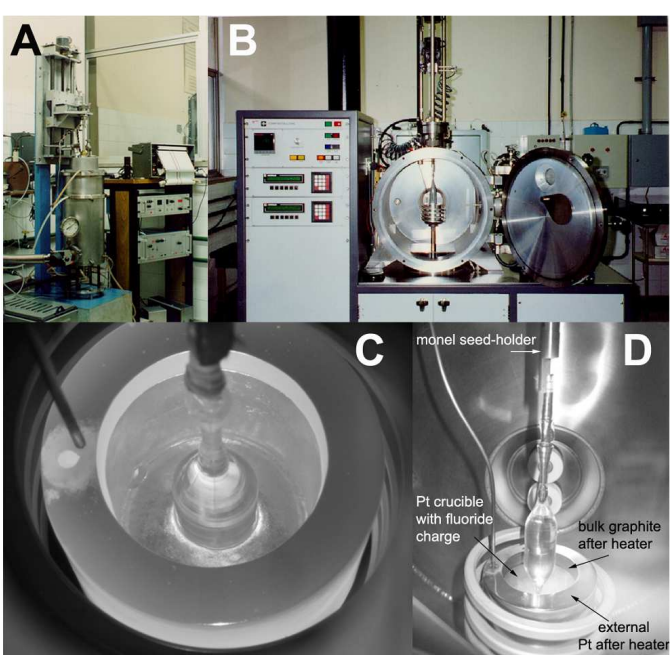

Fig. 1. (A) 1980 home-made resistive CZ furnace for fluorides crystal growth constructed at Crystal Growth Laboratory at CLA-IPEN, Brazil; (B) 1995 commercial induction $\mathrm{CZ}$ furnace to the growth of large crystals for laser rod preparation. Internal view of the $\mathrm{CZ}$ furnace for fluorides growth: (C) during a growth process and (D) after the cooling of the system with information of its components.

The usual materials for fluoride furnaces components are graphite (resistive elements, crucibles and after-heaters), and platinum (crucibles, seed holders and after-heaters), because neither the corrosive nature of the melt nor of the atmosphere affects them [9]. The typical material for oxides $\mathrm{CZ}$ systems, as $\mathrm{Al}_{2} \mathrm{O}_{3}$ and $\mathrm{ZrO}_{2}$ ceramics, should be eliminated from a fluoride $\mathrm{CZ}$ furnace, due to their low corrosion resistance to fluorides. As above mentioned, in view of the lower melting temperatures of fluorides, resistive furnaces are more easily applied than the inductive furnaces where the thermal gradient control (for temperatures below $1000^{\circ} \mathrm{C}$ ), is more challenging. As is well known, in $\mathrm{CZ}$ method the growth is dependent upon both the radial temperature gradient in the liquid and the vertical gradient through the length of the furnace. Similarly to oxides CZ furnace, the thermal gradients are adjusted by varying the number and positioning of graphite after-heaters and its dimensions. Conversely, graphite is not a thermal or an electrical insulator as the above mentioned ceramics; depending of its purity degree and porosity, it may absorb moisture, which influences the purity degree of the melt, and it has higher thermal conductivity which influences the heating set insulation and thus the thermal gradient in the crucible.

Platinum, platinum/gold and graphite are suitable materials for crucibles as they are not wetted by the fluoride melting. Thermal gradients in the system will change when using a platinum or a graphite (or vitreous carbon) crucible and/or after-heaters, as well as with their sizes, which are related to the desired crystal dimensions. 


\section{3. $\mathrm{Nd}^{3+}$ and other rare earth active ions in fluoride crystals}

Despite the extensive research on neodymium $\left(\mathrm{Nd}^{3+}\right)$ doped laser materials, it remains one of the most important active laser ions $[5,10]$. Concerning the fluoride family, YLF:Nd ( $\left.\mathrm{LiYF}_{4}: \mathrm{Nd}^{3+}\right)$ is one of the most important lasers, which is commercialized worldwide. The performance of YLF as a laser host induced the investigation of its isomorphs with rare-earth ions substituting the yttrium ion and/or mixed crystals of two lanthanides (i.e., $\mathrm{Li}(\mathrm{RE}) \mathrm{F}_{4}$ or $\mathrm{LiY}_{y}(\mathrm{RE})_{x}(\mathrm{RE})_{1-x-y} \mathrm{~F}_{4}$, where $\mathrm{RE}=$ rare earth) doped with $\mathrm{Nd}^{3+}$, and with other lanthanide active ions. This research includes not only the investigation of growth of these new potential laser crystals but also the analysis of their synthesis and purification process, study of phase diagrams of these compounds, and investigation of their laser properties.

In the pioneering work, published in 1961 by Thoma et al. [11], it was proposed a reevaluation of the phase relationships in the $\mathrm{LiF}-\mathrm{YF}_{3}$ system of a previously published work [12]. It was established the existence of the $\mathrm{LiYF}_{4}$ (YLF) compound which melted incongruently to $\mathrm{YF}_{3}$ at $819^{\circ} \mathrm{C}$ and $49 \mathrm{~mol} . \% \mathrm{YF}_{3}$. There was determined that this colorless compound was uniaxial positive, with the tetragonal structure of scheelite $\left(\mathrm{CaWO}_{4}\right)$ belonging to the space group $I 4_{1} / a$. Additionally, Thoma et al. [13] determined the phase diagrams for the systems $\mathrm{LiF}-$ $\mathrm{REF}_{3}(\mathrm{RE}=$ from La up to Lu), and observed that $\mathrm{Li}(\mathrm{RE}) \mathrm{F}_{4}$ (or RELF), was formed for the lanthanides with atomic number between 63 and 71 (from Eu to Lu). Concerning the melting behavior, it was established that the incongruence were reduced with the increase of the rare-earth atomic number, being congruent from HoLF up to LuLF.

The earliest reports of the growth of doped rare-earth YLF crystals has been made by Gabbe and Harmer in the late sixties to study the spectroscopic and their laser properties [14-16]. The crystals were grown by the $\mathrm{CZ}$ method, in argon atmosphere, from a non-stoichiometric composition. Starting materials were anhydrous $\mathrm{YF}_{3}$ and other RE trifluorides dried in HF, and single crystal chips of $\mathrm{LiF}$.

The congruent character of the RELF $(\mathrm{RE}=\mathrm{Y}$ or $\mathrm{Y}$, Ho, Er, Tm) melting was discussed by Pastor et al. [17]. Rare earth oxides of high purity were used in the fluoride synthesis under an atmosphere of hydrofluoric acid (HF) and helium (He). The crystal growth from the stoichiometric composition was performed by the $\mathrm{CZ}$ method in an atmosphere of $\mathrm{HF}-\mathrm{He}$ and pulling rate between 3 and $12 \mathrm{~mm} / \mathrm{h}$.

A comprehensive study of the systems $\mathrm{LiF}-\mathrm{REF}_{3}$, to the study of $\mathrm{LiREF}_{4}$ and mixed crystals, as $\mathrm{LiF}-\mathrm{ErF}_{3}-$ $\mathrm{YF}_{3}$, was conducted by Cockayne et al. [18-22]. The behavior of zone melted bars were investigated and the phase diagrams were constructed using differential thermal analysis (DTA) under an atmosphere of high purity argon (Ar) or HF. Pure crystals and solid solutions of $\mathrm{LiY}_{1-z} \operatorname{Er}_{x} \mathrm{Tm}_{y} \mathrm{Ho}_{z} \mathrm{~F}_{4}$ and $\mathrm{LiLu}_{1-x-y-z} \operatorname{Er}_{x} \operatorname{Tm}_{y} \mathrm{Ho}_{z} \mathrm{~F}_{4}$ were grown in $\mathrm{HF}$ or high purity Ar atmosphere. They concluded that the systems $\mathrm{LiF}-\mathrm{YF}_{3}, \mathrm{LiF}-\mathrm{ErF}_{3}$ and $\mathrm{LiF}-$ $\mathrm{ErF}_{3}-\mathrm{YF}_{3}$ have congruent melting when grown on a reactive or high purity argon atmosphere. Furthermore, that the main reason for the displacement of the stoichiometric composition was the contamination with oxygen impurities resulting in the formation of oxyfluorides, oxidation to $\mathrm{RE}_{2} \mathrm{O}_{3}$ or hydrolysis, which in consequence removes $\mathrm{REF}_{3}$ from the melt. Despite the growth of some crystals with the stoichiometric composition, they suggested that the use of an excess of 2 mol.\% LiF improved the crystal growth, once it compensates the dislocation from the stoichiometric composition caused by LiF evaporation. Other historical progresses in the $\mathrm{CZ}$ growth of these material family can be obtained in some reviews and references therein [23-26].

In recent years the research of new Nd laser hosts, presenting the same YLF properties, but with broader emission bandwidth and the possibility to accept high dopant concentration, without losses to the optical quality, is a goal to produce more efficient lasers. In our laboratories to the study of such new laser systems based on YLF or mixed crystals from the RELF family, the growth of high optical quality crystals by the $\mathrm{CZ}$ method are investigated. We start the process from high purity raw materials obtained from rare-earth oxide powders $(99.9 \%$ or better) by hydrofluorination at high temperature in $\mathrm{HF}$ atmosphere $[7,25]$. Additionally, LiF powder (99.9\% or better) is also zone-refined before it is added to the $\mathrm{REF}_{3}$ previously obtained. Single crystals are grown in a CZ furnace under a mixed high purity argon (99.9995\%) and $\mathrm{CF}_{4}(99.9999 \%)$ reactive atmosphere, and crystal-pulling rates are $0.5-1 \mathrm{~mm} / \mathrm{h}$.

Good results can also be obtained with the direct use of pure fluoride commercial powders (99.99\% or better), if a reactive atmosphere, such as $\mathrm{CF}_{4}$, is used during crystal growth process $[27,28]$ to prevent the reaction of rare earth fluorides with oxygen and moisture. However, the raw materials must be free of organic matter that may remain in the commercial compound, probably due to the production process of the rare-earth fluorides. Otherwise, the melt surface presents a carbon scum, making difficult the seeding process.

The effect of $\mathrm{CF}_{4}$ and other reactive gases in the growth of fluoride crystals was reported in detail by Pastor and others $[29,30]$. The HF reacts quickly with hydroxide $\left(\mathrm{OH}^{-}\right)$and oxide $\left(\mathrm{O}^{2-}\right)$ impurities but has no reaction with $\mathrm{H}_{2} \mathrm{O}$ in the environment. Water is the source of the hydrolysis reaction that introduces these anion impurities into the compounds. Carbon tetrafluoride, at high temperatures, converts $\mathrm{H}_{2} \mathrm{O}$ to $\mathrm{HF}$, based on the reaction: $\mathrm{CF}_{4}(\mathrm{~g})+2 \mathrm{H}_{2} \mathrm{O}(\mathrm{g}) \rightarrow \mathrm{CO}_{2}(\mathrm{~g})+4 \mathrm{HF}(\mathrm{g})$. For this reason, $\mathrm{CF}_{4}$ is considered useful as a secondary reactive agent to be used in addition to HF, for eliminating water in the environment. However, for some fluorides as YLF or RELF, the $\mathrm{CF}_{4}$ can be used as a primary reactive processing atmosphere agent with satisfactory results [4].

RELF crystals are very sensitive to diameter variation, 
if this occurs during the $\mathrm{CZ}$ pulling, in general, it presents micro scattering centers. They can be formed by the precipitation of a secondary phase when an excess of the components is present, other causes are the contamination with oxygen impurities and the trapping of the environment gas forming voids or bubbles. An example of observable defects can be seen in Fig. 2; a $\langle 100\rangle$-oriented $\mathrm{GdLiF}_{4}$ (GLF) crystal doped with Nd which presented a very sudden change in diameter, and in consequence a cloud of defects, formed in this region. Planes of macro defects formed parallel to the plane (110) and they were elongated when observed under a light microscope. These inclusions seem to be filled with a foreign phase.
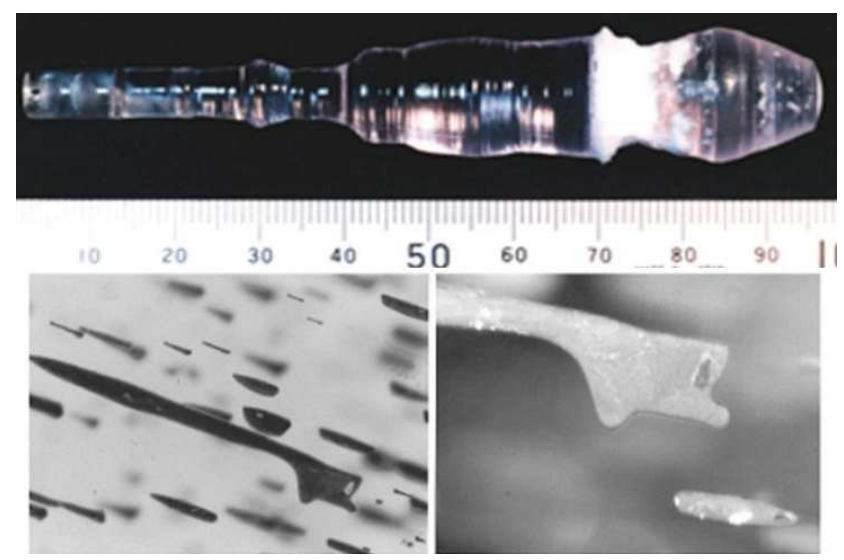

Fig. 2. A GLF:Nd crystal presenting a sudden variation of diameter (above); and details of the formed defects observed on a light microscope (below) [28].

Several fluoride crystals have been studied in our laboratories to compare YLF with its isomorphs relating to optical quality, spectroscopic and laser properties, as for example crystals of YLF:Nd and GLF:Nd [31-33] and solid solutions of the type-LiY $\mathrm{L}_{1-x} \operatorname{Ln}_{x} \mathrm{~F}_{4}: \mathrm{Nd}(\mathrm{Ln}=\mathrm{Gd}$ or $\mathrm{Lu}$ ) [34-36] and $\mathrm{LiGd}_{1-x} \mathrm{Lu}_{x} \mathrm{~F}_{4}: \mathrm{Nd}$. Particularly, to the growth of such mixed crystals the phase relations must be known, so the melting behaviors of the solid solutions formed in the systems $\mathrm{LiF}-\mathrm{YF}_{3}-\mathrm{GdF}_{3}$ and $\mathrm{LiF}-$ $\mathrm{GdF}_{3}-\mathrm{LuF}_{3}$ system were studied and the phase diagrams for both systems were obtained experimentally and assessed by computational thermodynamics [37, 38].

As main results of these studies two new host materials could be developed: (a) the crystal $\mathrm{LiY}_{0.5} \mathrm{Lu}_{0.473} \mathrm{Nd}_{0.027} \mathrm{~F}_{4}$ (LuYLF:Nd), to which it was observed that the interaction of the $\mathrm{Nd}$ ions was enhanced resulting in an enlargement of $24 \%$ of the emission bands of the Nd relative to YLF:Nd. It was demonstrated that this crystal has better properties to those of the crystal YLF:Nd, and temporal pulse width of 4 ps were obtained [39]; and (b) the crystal $\mathrm{LiGd}_{0.5} \mathrm{Y}_{0.473} \mathrm{Nd}_{0.027} \mathrm{~F}_{4}$ (GdYLF:Nd), which proved effective in obtaining a single frequency laser pumped by laser diode [40, 41]. This active medium showed a tuning range of $150 \mathrm{GHz}$, with a maximum of $200 \mathrm{~mW}$ of output power at the center of the tuning range. In this scheme multimode laser operated with an output power of $320 \mathrm{~mW}$ for the same pumping power, $2.8 \mathrm{~W}$. Both crystals grown by $\mathrm{CZ}$ method are shown in Fig. 3.
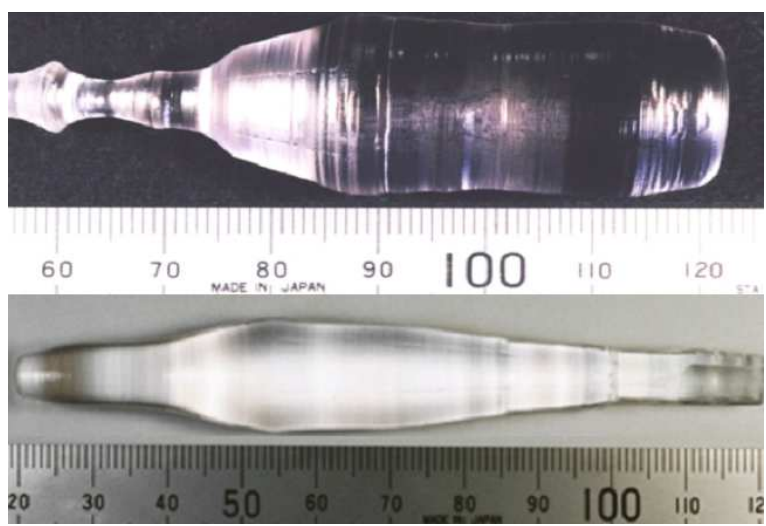

Fig. 3. As-grown crystals of LuYLF: Nd (above) and GdYLF: Nd (below) [35].

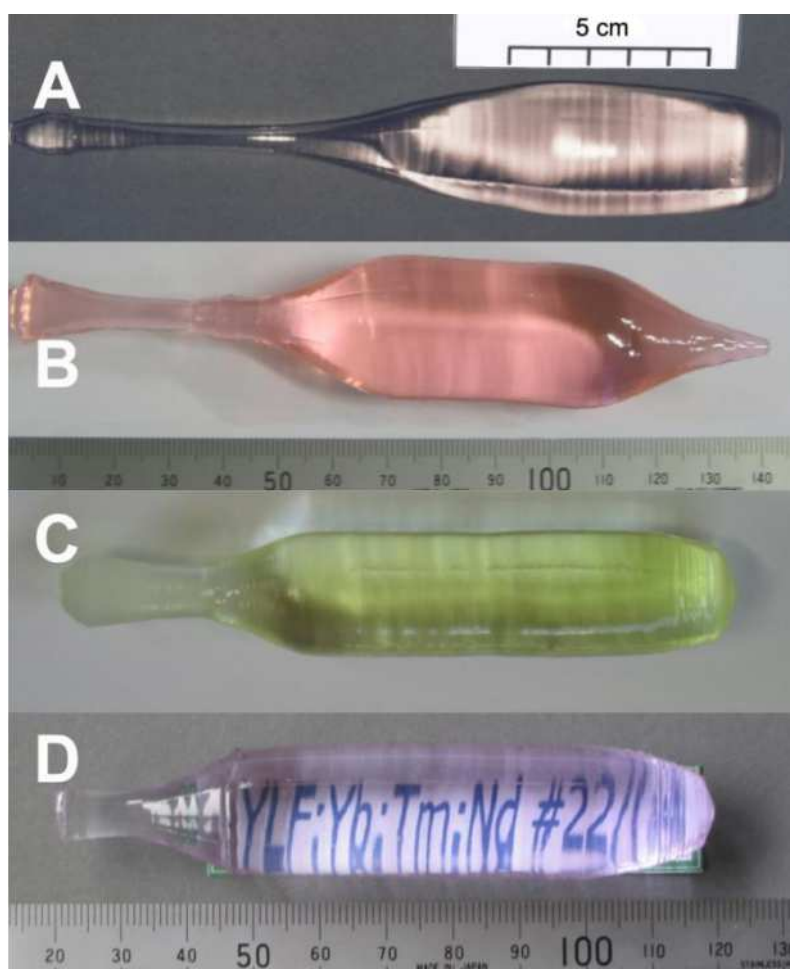

Fig. 4. Crystals grown by the $\mathrm{CZ}$ method at IPEN for laser developments: (A) YLF:Nd; (B) YLF crystal doped with 15 mol.\% of Er; (C) YLF crystal doped with 2 mol.\% Pr; (D) YLF crystal doped with 20 mol.\% Yb, $1.3 \mathrm{~mol} . \% \mathrm{Nd}$ and $0.05 \mathrm{~mol} . \% \mathrm{Tm}$ (in the melt).

With the advance of semiconductor diode lasers, new pumping schemes and new types of practical and compact laser devices were developed. In fact, nowadays the diode pumped lasers has a vast field of study, with new 
possibilities of resonator settings using powerful diode lasers. Time-resolved luminescence spectroscopy allied to laser tests is an efficient method to develop new compact diode pumped lasers. Similar to the classical flash-lamp pumped lasers, for diode pumped lasers crystals, high optical quality is also required and the $\mathrm{CZ}$ method continues to be the best technique to obtain these laser media. Some examples of developments achieved in our laboratories on this field are:

(A) a new cavity design for passively $Q$-switched YLF:Nd lasers provided more than $100 \mathrm{~kW}$ peak power with up to $1 \mathrm{kHz}$ at $1053 \mathrm{~nm}$ (the crystal can be seen in Fig. 4A). A compact and robust cavity achieves TEM00 mode by means of a new technique based on two bounces inside the crystal. Very stable operation with less than $0.9 \%$ overall energy fluctuations could be maintained during a test period of $30 \mathrm{~min}$ [42-44];

(B) the energy transfer rates and the population inversion of the ${ }^{4} I_{11 / 2}$ excited state of $\mathrm{Er}^{3+}$ was calculated by means of numerical solutions of the rate equations system in YLF:Er (15 mol.\%) crystal (Fig. 4B). This study allowed obtaining a quasi-continuous pumped laser in this crystal at $2.8 \mu \mathrm{m}$ for the first time. The laser generates higher average output power when operated at $250 \mu \mathrm{s}$ pulse duration than for longer pulses;

(C) passively $Q$-switched YLF:Pr laser was demonstrated for the first time operating at $640 \mathrm{~nm}$ [45] (the grown crystal can be seen in Fig. $4 \mathrm{C}$ ). A $4 \times 4 \mathrm{~mm}$ cross-section and $7 \mathrm{~mm}$ long crystal was cut from this boule. It was pumped using a commercial GaN diode laser delivering up to $409 \mathrm{~mW}$ at $444 \mathrm{~nm}$ with its polarization aligned for maximum absorption in the YLF:Pr crystal, i.e. along the $c$-axis. The minimum pulse duration of $145 \mathrm{~ns}$ was obtained at the output power of $23 \mathrm{~mW}$ (slope efficiency of $11 \%$ ) and repetition rate of $\approx 100 \mathrm{kHz}$;

(D) the use of Nd as a second sensitizer for YLF:Yb:Tm crystals improves the upconversion mechanism that gives rise to the Tm blue emission in $480 \mathrm{~nm}$ (Fig. 4D) [46]. Results of spectroscopic studies and numerical simulation of the rate equations system showed that a population inversion for $480 \mathrm{~nm}$ laser emission line is attained for a pumping rate threshold of $26 \mathrm{~s}^{-1}$, which is equivalent to an intensity of $880 \mathrm{~W} \mathrm{~cm}^{-2}$ for a continuous laser pumping at $797 \mathrm{~nm}$ [47].

\section{Transition metals active ions in fluoride crystals}

Important ions of the transition metal group include $\mathrm{Cr}^{3+}, \mathrm{V}^{2+}, \mathrm{Co}^{2+}$ and $\mathrm{Ni}^{2+}$ that resulted in the called "vibronic" lasers. They are obtained from broad-band absorption and emission characteristic of these ions, due to the interaction between the lasing ion and the crystal field of the host lattice, resulting in tunable solid-state lasers. The first vibronic laser was reported in 1963 with a Ni-doped $\mathrm{MgF}_{2}$ crystal [48] and in sequence a series of similar systems ( $\mathrm{Ni}, \mathrm{Co}, \mathrm{V}$ in $\mathrm{MgF}_{2}, \mathrm{MnF}_{2}, \mathrm{ZnF}_{2}$ and $\mathrm{KMgF}_{3}$ ) were studied but these lasers presented a disadvantage, they operated only when cooled to cryogenic temperatures [5]. Only many years later a room temperature vibronic laser was reported; some authors considered that it was a flash lamp-pumped $\mathrm{Ho}: \mathrm{BaY}_{2} \mathrm{~F}_{8}$ device emitting at $2.17 \mu \mathrm{m}[49,5]$, others that the first room temperature vibronic laser was discovered when researchers were exploring the properties of $\mathrm{BeAl}_{2} \mathrm{O}_{4}: \mathrm{Cr}^{3+}$ $[50,51]$. In any case, it is consensus that the successful demonstration of tunable laser emission (at cryogenic temperatures), from $\mathrm{Co}^{2+}, \mathrm{V}^{2+}, \mathrm{Ni}^{2+}$ in $\mathrm{MgF}_{2}$ became a model for all later useful tunable laser materials, such as Ti-sapphire. Laser action at room temperature on $\mathrm{MgF}_{2}$ :Co was obtained only in 1988 [52].

The growth process of alkaline earth fluorides as $\mathrm{MnF}_{2}$, $\mathrm{MgF}_{2}$ and $\mathrm{ZnF}_{2}$ doped with transition metals as $\mathrm{Ni}$ and Co was initially performed by the Bridgman-Stockbarger or vertical freeze technique [53] in sealed crucibles, because of a widespread view that these crystals could not be grown from the melt in an open system due to the high volatility of the dopant species. Only in 1985 it was reported that $\mathrm{CZ}$ growth of large oriented crystals was possible because the volatilization loss was not a critical issue in the growth of $\mathrm{MgF}_{2}$ : Co or $\mathrm{MgF}_{2}: \mathrm{Ni}$ crystals, when care was given to powder charge preparation and elimination of $\mathrm{OH}^{-}$during the growth process [54]. Furthermore, it was observed that dopant losses occurred by reduction of the transition metal ion to its elemental form arising from the melting of these materials in carbon crucibles. The loss mechanism was explained on Co-doped $\mathrm{MgF}_{2}$ growth considering that moisture would initiate the reduction by the formation of the metal oxide according to reactions: $\mathrm{CoF}_{2}+\mathrm{H}_{2} \mathrm{O} \rightarrow \mathrm{CoO}+2 \mathrm{HF}$ and $2 \mathrm{CoO}+\mathrm{C} \rightarrow 2 \mathrm{Co}+\mathrm{CO}_{2}$.

We observed similar problem in the growth of $\mathrm{Ni}$ - or Co-doped $\mathrm{BaLiF}_{3}$ (BLF) single crystals [55]. This crystal, similar to $\mathrm{KMgF}_{3}$, was considered in the nineties also a potential host for vibronic lasers. For the development and study of laser properties, several studies on the synthesis and growth conditions of pure and $\mathrm{Ni}, \mathrm{Co}$-doped $\mathrm{BaLiF}_{3}$ were performed by our group [56-59].

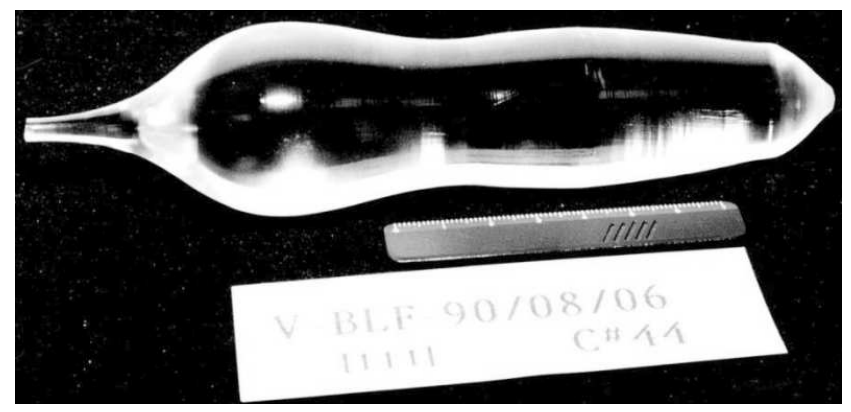

Fig. 5. Large BLF crystals growth by CZ method under $\mathrm{Ar}$ and $\mathrm{CF}_{4}$ atmosphere.

The BLF crystal is an inverse perovskite with cubic structure, where monovalent ion $\mathrm{Li}^{+}$is at the center of an $\mathrm{F}_{6}$ octahedron, whereas the $\mathrm{Ba}^{2+}$ divalent ions are in the 12 -fold environment site, resulting in a different crystal field interaction from classic perovskite structures like 
the observed on $\mathrm{KMgF}_{3}$ crystals. This compound melts incongruently and a single crystal must be grown from a non-stoichiometric melt $\left(43 \% \mathrm{BaF}_{2}: 57 \% \mathrm{LiF}\right)$ to avoid other phase precipitation. To avoid oxyfluoride impurities in our experiments a reactive atmosphere processing $\left(\mathrm{CF}_{4}\right.$ and $\left.\mathrm{HF}\right)$ was used in the synthesis and growth process. Initially, pure crystals were grown in a vacuum-tight resistive $\mathrm{CZ}$ furnace, and there were evaluated the optical and crystalline quality, associated with the preparation conditions and growth process. Interferometry and neutron diffraction allowed to correlate optical and crystalline quality of BLF single crystals with uniformity, growth direction and rotation rates. Suitable growth conditions to assure an almost flat solid-liquid interface were determined allowing the growth of large boules of relatively stress-free crystals (Fig. 5) [56, 57].

$\mathrm{NiF}_{2}$ (or $\mathrm{CoF}_{2}$ ) compounds and pieces of the pre-crystallized BLF crystals were melted in a $\mathrm{CZ}$ resistive furnace under an argon atmosphere. A platinum (Pt) crucible was used for pure BLF melts but for Ni and Co-doped BLF it was necessary to use a vitreous carbon crucible to avoid $\mathrm{Pt} /$ transition metal alloys formation. Even though careful pre-treatment of the system under vacuum and purification of the argon gas introduced in the furnace, the formation of a thin film on the melt surface was observed. This metallic "scum" adhered to the crucible walls or, in some of the growth runs, to the growing crystal resulting in diameter variations and defects (Fig. 6A). To minimize this problem, the $\mathrm{CZ}$ growth runs were performed under a reactive atmosphere $\left(\mathrm{CF}_{4}\right)$, which reduced the metallic thin-film formation allowing the growth of good quality crystals as the ones showed in Fig. 6B and C [55]. However, low dopant incorporation was observed for both transition metals. Latter work, where the Ni distribution in BLF was studied by zone melting under HF flow, showed that the low incorporation of $\mathrm{Ni}$ in this matrix was not only because of the oxidation and reduction reactions, also observed on the $\mathrm{MgF}_{2}: \mathrm{Ni}$, Co growth, but in addition because of the low segregation coefficient of $\mathrm{Ni}^{2+}$ in BLF [59]. The presence of metallic Ni was not observed in the surface of the $\mathrm{HF}$ refined ingots. It is also interesting to mention that different from expected, it was observed from extended $\mathrm{X}$-ray absorption fine-structure (EXAFS) measurements that the $\mathrm{Ni}^{2+}$ dopant in BLF predominantly substitutes on the $\mathrm{Li}^{+}$site of the host lattice instead of $\mathrm{Ba}^{2+}$ site [60].

Several studies of the optical properties of $\mathrm{Ni}$ or $\mathrm{Co}-$ -doped crystals [61-63] showed that although these crystals with cubic perovskite-like structures showed potential laser properties for new laser systems emitting on $1.5 \mu \mathrm{m}$ region, on both ( $\mathrm{Ni}$ and $\mathrm{Co}$ ) laser operation would be possible only on cryogenic temperatures. However, all the earlier research efforts on the growth development of fluorides doped with transition metal ions indirectly contributed into development of more modern vibronic laser materials, as for example, LiSAF:Cr, investigated since 1989 and nowadays is an important host for ultra-short laser systems.

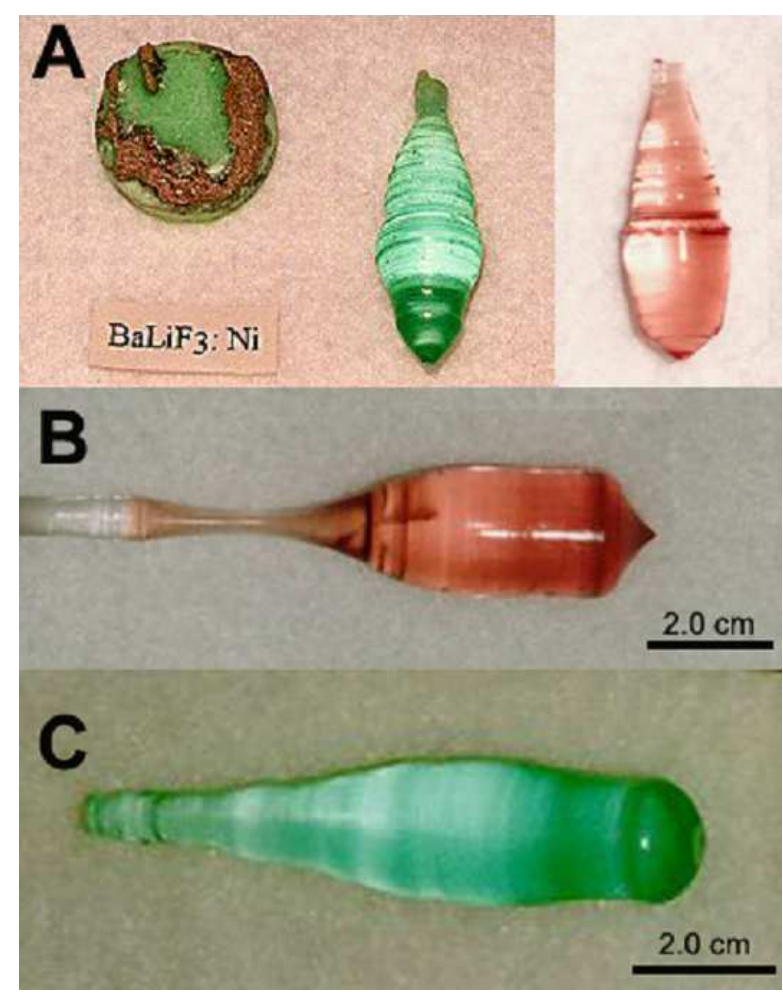

Fig. 6. (A) BLF:Ni residual charge after $\mathrm{CZ}$ growth under Ar showing solidified metallic film and, as-grown crystals of BLF:Ni and BLF:Co obtained under such growth conditions showing diameter variations and defects; (B) BLF:Co and (C) BLF:Ni CZ as-grown crystals, from experiments performed under a reactive atmosphere of $\mathrm{CF}_{4}$ [55].

In 1988 Payne et al. [64] demonstrated laser action on LiCAF:Cr (and LiSAF:Cr [65]) crystals (at room temperature) stimulating the research on other Cr-doped colquiriite-type fluoride crystals. The most crucial points in the growth of these laser hosts are the elimination of scattering losses due to defect formation and cracks due to the thermal stress. Although those crystals can be grown by different growth methods, large crystals with low optical losses, suitable for laser rods, are produced only by the $\mathrm{CZ}$ method [50].

DeYoreo et al. [66] reported that annealing $\mathrm{LiCAF}$ crystals at $795^{\circ} \mathrm{C}$ removes the defects believed to be due to ex-solvation of crystalline particles. Klimm and Reiche [67] reported that density of scattering particles can only be reduced substantially by annealing LiCAF crystals at $20 \mathrm{~K}$ below the melting point. They also proposed that evaporation of lithium-aluminum-fluorides during the crystal growth process of LiCAF and LiSAF leads to an enrichment of the melt with $\mathrm{CaF}_{2}$ (or $\mathrm{SrF}_{2}$ ). The non-stoichiometry condition during the growth results in the precipitation of calcium (and in a lower extent of $\mathrm{SrF}_{2}$ ) with formation of micro defects. The defects are assumed to be related to water and/or oxygen impurities within the starting materials and growth atmosphere, as well as to peculiarities of phase diagram of $\mathrm{LiF}-\mathrm{CaF}_{2}-$ 
$\mathrm{AlF}_{3}$ system. Crystals of LiSAF grown under similar conditions contain fewer precipitates than LiCAF. This might be due to smaller evaporation losses in view of its lower melting point. Because of the high losses on $\mathrm{LiCAF}$ the reported laser performance of this $\mathrm{Cr}$-doped host was poor and, consequently, laser developments was mostly done on LiSAF:Cr.

In our studies of Cr-doped LiSAF crystals we also observed $\mathrm{CrF}_{3}$ oxidation (similarly to other transition metals) during the growth process. We showed that a synthesis with a HF atmosphere and growth by zone melting eliminate this problem that usually affects the crystalline quality of such crystals. The $\mathrm{CrF}_{3}$ oxidation is a reversible process and can be controlled by appropriate thermal treatment. We obtained small LiSAF:Cr crystals with high optical quality, uniform dopant distribution and excellent laser performance with the growth by zone melting technique under $\mathrm{HF}$ flow $[68,69]$.

It is then clear that in the growth of large LiSAF:Cr crystals by the $\mathrm{CZ}$ method, for laser rod preparation, the purity of the reagents and the atmosphere are critical factors to be controlled. We observed in the $\mathrm{CZ}$ growth experiments of bulk LiSAF:Cr under a mixed $\mathrm{Ar}$ and $\mathrm{CF}_{4}$ atmosphere that chromium oxide particles formed. Because of the usually intense thermal convection in the $\mathrm{CZ}$ process, these particles were usually distributed throughout the melt and typically settle to the growing interface resulting in cracked crystals. It is important to note that, taking into account the lower melting temperature of these fluorides, the $\mathrm{CF}_{4}$ reaction with water in the growth environment is not as effective as the observed in other fluoride crystals growth. However, this problem can be eliminated with the suitable pre-synthesis, under $\mathrm{HF}$, of the LiSAF:Cr starting charge to be used on $\mathrm{CZ}$ growth.

A further important topic in the growth of LiSAF:Cr crystals is the thermal gradient. Non-homogeneous regions can form in a crystal due to tension sources introduced by agglomeration of defects, variations in the composition or inclusions; however, the largest source of stress in crystals growing is the one exactly introduced by the need to remove heat to the outside of the surface to obtain solidification. This process necessarily results in non-homogeneous distribution of temperature inducing stress due to non-homogeneity of thermal expansion in the body of the crystal. The highly anisotropic thermal expansion of LiSAF and LiCAF is the main reason for easy crack formation in large $\mathrm{CZ}$ crystals.

According to the analysis of thermo-mechanical properties of LiSAF described by Klimm et al. [70], any treatment of these crystals that produce non-linear thermal gradients must be carried out very carefully. The LiSAF crystal presents a strongly anisotropic nature, being the values of the thermal expansion coefficient of this matrix, at ambient temperature, equal to: $\alpha(\times 1)=\alpha(\times 2)=$ $18.8 \times 10^{-6}{ }^{\circ} \mathrm{C}^{-1}$ and $\alpha(\times 3)=-10.0 \times 10^{-6}{ }^{\circ} \mathrm{C}^{-1}$. In other words, during the heating, there is a thermal expansion along the $\boldsymbol{a}$ direction and one thermal contrac- tion along $c$ direction of the crystal cell.

From our experience with fluoride crystals growth we know that the temperature distribution for fluorides, in general, depend not only of the thermal contour conditions (system), but also of the flow in the melt (i.e., inside the crucible). Theoretical studies [71] have demonstrated that the magnitude of the Prandtl number $(\mathrm{Pr})$ serves as a measure of the relative importance of heat transfer by conduction or convection in a growth system. For fluorides high values of $\operatorname{Pr}\left(\operatorname{Pr}_{\mathrm{LiF}} \approx 0.98\right)$ were already observed indicating that the flow configuration in the crucible will be influenced by convection, and the form of the interface will change according to the isotherms near the crystal, which may vary from convex (natural convection dominant) to the concave (forced convection dominant) with the rotation of the crystal. This effect was demonstrated experimentally in the growth of pure BLF crystals [56].

In order to obtain a low and linear temperature gradient desired to the growth of large boules of LiSAF:Cr, by the $\mathrm{CZ}$ method, we adjusted experimentally: the heating set (crucible, after-heaters and induction coil) of our induction heated furnace and the rotation rate applied during the growth process. It is interesting to note that lower temperature gradients are important not only for controlling thermal stresses but also to control the selective evaporation from LiSAF (or LiCAF).

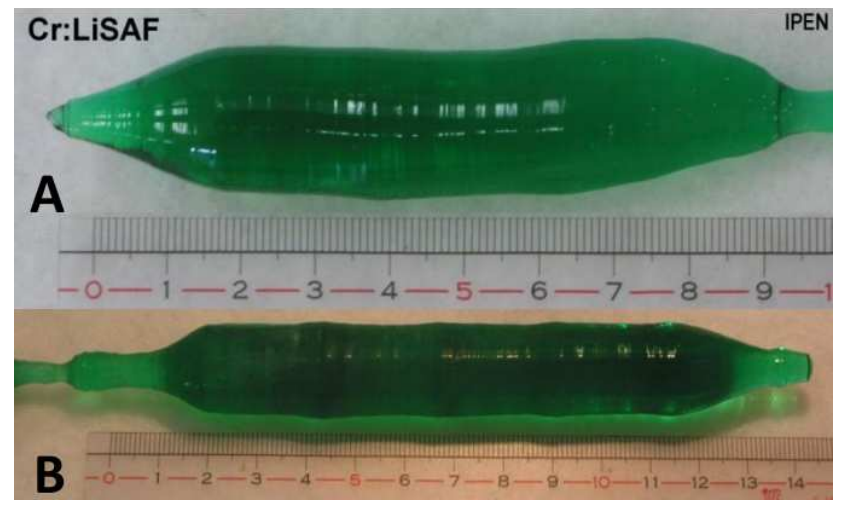

Fig. 7. As-grown LiSAF:Cr crystals obtained during CZ crystal growth study at CLA-IPEN, to the development of large boules with uniform dopant distribution: (A) one of the first LiSAF:Cr crystal obtained from a non-perfectly oriented seed (it is interesting to note the adjustment of the misorientation from the cone region of the boule), but highly transparent and uniform in diameter; (B) optimized $110 \mathrm{~mm}$ long crystal with homogeneous diameter and no cracks.

Figure 7 shows examples of the obtained crystals during this study; large LiSAF:Cr crystals were grown along the $a$ axis, with pulling rates of $1 \mathrm{~mm} / \mathrm{h}$ and rotation rates of 15 to $20 \mathrm{rpm}$ (crucibles diameter equals to $60 \mathrm{~mm}$ ) assuring almost radially flat isotherms in the crystallization interface. Several developments on laser technology were also achieved from LiSAF:Cr crystals at the Center for Laser and Applications [72-74]. 


\section{Conclusion}

The advances on laser systems based on single crystals, and potential new applications of this technology, will always be integrated with the development and/or improvement of crystal growth research. The overview of our results on YLF and its rare earth isomorphs (RELF) crystals, including solid solutions of the type$-\mathrm{LiY}_{1-x} \mathrm{Ln}_{x} \mathrm{~F}_{4}(\mathrm{Ln}=\mathrm{Gd}$ or $\mathrm{Lu})$ and $\mathrm{LiGd}_{1-x} \mathrm{Lu}_{x} \mathrm{~F}_{4}$, showed clearly this affirmation. Crystal growth, optical quality, spectroscopic and laser properties of several crystals have been studied, simultaneously with the developments of new pumping schemes and new practical and higher performance fluoride laser devices based on rare earth active ions as $\mathrm{Nd}, \mathrm{Er}, \mathrm{Pr}, \mathrm{Yb}$, and $\mathrm{Tm}$.

The CZ method has been very useful for laser progress allowing the increase of the crystals quality, through the understanding of the nature and sources of defects that reduce the laser efficiency, and establishing new approaches to the growth of enhanced laser media. The fast progress of new ultra-short laser systems based on LiSAF:Cr crystals was for sure obtained due to all the earlier research efforts, shortly reported here, on the growth of transition metal ions doped fluorides (as $\mathrm{MgF}_{2}$, and BLF), aiming vibronic laser development at room temperature.

In fact, to the growth of large boules for laser rods of high power systems or smaller crystals for compact diode laser pump schemes, the $\mathrm{CZ}$ method continues as the better option to the growth of high quality laser crystals. We believe that as the physics and chemistry of laser crystals come to be better understood and equipment technology progresses, continued advances will be performed by using the Czochralski growth concepts.

\section{Acknowledgments}

This work was performed at the Center for Laser and Applications of the Nuclear and Energy Research Institute - IPEN/CNEN-SP. The authors acknowledge M.Sc. Jair R. de Moraes for his help in the preparation of the figures of this article. Figure $2 \mathrm{~b}$ is reprinted from Ref. [28]; Fig. 3 is reprinted from Ref. [35], and Fig. 6b,c is reprinted from Ref. [55], all with permission from Elsevier.

\section{References}

[1] D.T. Hurle, Crystal Pulling from the Melt, Springer Verlag, Berlin 1993.

[2] K. Nassau, A.M. Broyer, J. Appl. Phys. 33, 3064 (1962).

[3] H. Li, J. Xu, in: Springer Handbook of Crystal Growth, Eds. G. Dhanaraj, K. Byrappa, V. Prasad, M. Dudley, Springer, Berlin 2010, p. 479.

[4] S.L. Baldochi, S.P. Morato, in: Encyclopedia of Materials: Science and Technology, Eds. K.H.J. Buschow, R.W. Cahn, M.C. Flemings, B. Ilschner, E.J. Kramer, S. Mahajan, P. Veyssière, Elsevier Science, Oxford 2001, p. 3200.
[5] W. Koechner, Solid State Laser Engineering, Springer, Berlin 1999.

[6] I.M. Ranieri, S.L. Baldochi, A.M.E. Santo, L. Gomes, L.C. Courrol, L.G. Tarelho, W. de Rossi, J.R. Berreta, F.E. Costa, G.E.C. Nogueira, N.U. Wetter, D.M. Zezell, N.D. Vieira Jr., S.P. Morato, J. Cryst. Growth 166, 423 (1996).

[7] G. Guggenheim, J. Appl. Phys. 34, 2482 (1963).

[8] R.C. Pastor, M. Robinson, Mater. Res. Bull. 11, 1327 (1976).

[9] R. Robinson, D.M. Cripe, J. Appl. Phys. 37, 2072 (1966).

[10] G. Huber, C. Kränkel, K. Petermann, J. Opt. Soc. Am. 27, B93 (2010).

[11] R.E. Thoma, C.F. Weaver, H.A. Friedman, H. Insley, L.A. Harris, H.A. Yakel, J. Phys. Chem. 65, 1096 (1961).

[12] E.P. Degunov, Dokl. Akad. Nauk SSSR 60, 1185 (1948).

[13] R.E. Thoma, G.D. Bruton, R.A. Penneman, T.K. Keenan, Inorg. Chem. 9, 1096 (1970).

[14] D. Gabbe, A.L. Harmer, J. Cryst. Growth 3, 544 (1968).

[15] A.L. Harmer, A. Linz, D. Gabbe, L. Gillespie, G.M. Janney, E. Sharp, Bull. Am. Phys. Soc. 12, 1068 (1967)

[16] E.J. Sharp, D.J. Horowitz, J.E. Miller, J. Appl. Phys. 44, 5399 (1973).

[17] R.C. Pastor, M. Robinson, M. Akutagawa, Mater. Res. Bull. 10, 501 (1975).

[18] J.S. Abell, I.R. Harris, B. Cockayne, J.G. Plant J. Mater. Sci. 11, 1807 (1976).

[19] J.S. Abell, I.R. Harris, B. Cockayne, J. Mater. Sci. 12, 670 (1977).

[20] H. Safi, I.R. Harris, B. Cockayne, J.G. Plant, J. Mater. Sci. 16, 3203 (1981).

[21] B. Cockayne, J.G. Plant, R.A. Clay, J. Cryst. Growth 54, 407 (1981).

[22] I.R. Harris, H. Safi, N.A. Smith, M. Altunbas, B. Cockayne, J.G. Plant, J. Mater. Sci. 18, 1235 (1983).

[23] L.R. Batsanova, Russ. Chem. Rev. 40, 465 (1971).

[24] P.J. Walker, Prog. Cryst. Growth Charact. 3, 103 (1980).

[25] N.D. Vieira Jr., I.M. Ranieri, L.V.G. Tarelho, N.U. Wetter, S.L. Baldochi, L. Gomes, P.S.F. deMatos, W. deRossi, G.E.C. Nogueira, L.C. Courrol E.A. Barbosa, E.P. Maldonado, S.P. Morato, J. Alloys Comp. 344, 231 (2002).

[26] B.P. Sobolev, Crystallogr. Rep. 47, S63 (2002).

[27] S.L. Baldochi, K. Shimamura, K. Nakano, N. Mujilatu, T. Fukuda, J. Cryst. Growth 205, 537 (1999).

[28] I.M. Ranieri, K. Shimamura, K. Nakano, T. Fujita, L.C. Courrol, S.P. Morato, T. Fukuda, J. Cryst. Growth 217, 145 (2000).

[29] R.C. Pastor, A.C. Pastor, Mater. Res. Bull. 10, 117 (1975).

[30] R.C. Pastor, M. Robinson, M. Braunstain, Mater Res. Bull. 15, 469 (1980). 
[31] L.C. Courrol, I.M. Ranieri, L. Gomes, Radiat. Eff. Defect S. 149, 369 (1999).

[32] L.C. Courrol, E.P. Maldonado, L. Gomes, N.D. Vieria Jr., I.M. Ranieri, S.P. Morato, Opt. Mater. 14, 81 (2000).

[33] E.P. Maldonado, I.M. Ranieri, S.P. Morato, N.D. Vieira Jr., Trends Opt. Photon. Ser. 10, 444 (1997).

[34] I.M. Ranieri, S.P. Morato, L.C. Courrol, H.M. Shihomatsu, A.H. Bressiani, N.M.P. Moraes, J. Cryst. Growth 209, 906 (2000).

[35] I.M. Ranieri, S.P. Morato, A.H. Bressiani, L.C. Courrol, E.P. Maldonado, N.U. Wetter, N.D. Vieira Jr, S.L. Baldochi, K. Shimamura, T. Fukuda, J. Alloys Comp. 344, 203 (2002).

[36] I.M. Ranieri, K. Shimamura, K. Nakano, T. Fujita L.C. Courrol, S.P. Morato, T. Fukuda, J. Cryst. Growth 217, 145 (2000).

[37] I.M. Ranieri, Ph.D. Thesis, IPEN, University of Săo Paulo, Săo Paulo, Brazil Available from: http:// pelicano.ipen.br/PosG30/inicio.php .

[38] I.A. Santos, Ph.D. Thesis, IPEN, University of Săo Paulo, Săo Paulo, Brazil 2012. Available from: http://www . teses.usp.br/teses/disponiveis/85/ 85134/tde-08032013-151744/.

[39] E.P. Maldonado, E.A. Barbosa, L.C. Courrol, N.U. Wetter, I.M. Ranieri, S.P. Morato, N.D. Vieira Jr., Opt. Eng. 40, 1573 (2001).

[40] N.U. Wetter, P.S.F. de Mattos, I.M. Ranieri, L.C. Courrol, S.P. Morato, Opt. Commun. 204 311 (2002).

[41] E.P. Maldonado, N.U. Wetter, I.M. Ranieri, E.A. Barbosa, L.C. Courrol, S.P. Morato, N.D. Vieira Jr., Trends Opt. Photon. Ser. 26, 642 (1999)

[42] A.M. Deana, I.M. Ranieri, S.L. Baldochi, N.U. Wetter, Appl. Phys. B 106, 877 (2012).

[43] N.U. Wetter, E.C. Sousa, I.M Ranieri, S.L. Baldochi, Opt. Lett. 34, 292 (2009).

[44] N.U. Wetter, E.C. Sousa, F.A. Camargo, I.M. Ranieri, S.L. Baldochi, J. Opt. A, Pure Appl. Opt. 10, 104013 (2008).

[45] V.G. Savitski, I.M. Ranieri, A.B. Krysa, S. Calvez, in: Conf. on Lasers and Electro-Optics (CLEO), Optical Society of America, Washington 2011.

[46] I.M. Ranieri, L.C. Courrol, A.F. Carvalho, L. Gomes, S.L. Baldochi, J. Mater. Sci. 42, 2309 (2007).

[47] A.F.H. Librantz, L. Gomes, L.C. Courrol, I.M. Ranieri, S.L. Baldochi, J. Appl. Phys. 105, 113503 (2009)

[48] L.F. Johnson, R.E. Dietz, H.J. Guggenheim, Phys. Rev. Let. 11, 318 (1963).

[49] L.F. Johnson, H.J. Guggenheim, IEEE J. Quant. Electron. QE-10, 442 (1974).

[50] L.J. Atherton, S.A. Payne, C.D. Brandle, Ann. Rev. Mater. Sci. 23, 453 (1993).

[51] J.C. Walling, O.G. Peterson, H.P. Jenssen, R.C. Morris, E.W. O'Dell, IEEE Quant. Electron. 16, 1302 (1980).
[52] D. Welford, P.F. Moulton, Opt. Lett. 13, 975 (1988).

[53] T.B. Reed, R.E. Fahey, P.F. Moulton, J. Cryst. Growth 42, 569 (1977).

[54] M. Robinson, L.G. DeShazer, J. Cryst. Growth 71, 95 (1985).

[55] S.L. Baldochi, A.M.E. Santo, E. Martins, M. Duarte, M.M.F. Vieira, N.D. Vieira Jr., S.P. Morato, J. Cryst. Growth 166, 375 (1996).

[56] S.L. Baldochi, J.Y. Gesland, Mater. Res. Bull. 27 , 891 (1992).

[57] S.L. Baldochi, V.L. Mazzocchi, C.B.R. Parente, S.P. Morato, Mater. Res. Bull. 29, 1321 (1994).

[58] S.L. Baldochi, Ph.D. Thesis, IPEN, University of Săo Paulo, Săo Paulo, Brazil 1993. Available from: http: //www. ipen.br/biblioteca/teses/20069.pdf .

[59] A.M.E. Santo, S.P. Morato, S.L. Baldochi, J. Cryst. Growth 203, 156 (1999).

[60] A.V. Chadwick, S.R. Davisy, J.F. de Lima, M.E.G. Valério, S.L. Baldochi, J. Phys. Condens. Matter 8, 10679 (1996).

[61] E. Martins, N.D. Vieira Jr., S.L. Baldochi, S.P. Morato, J.Y. Gesland, J. Lumin. 62, 281 (1994).

[62] M. Duarte, E.M., S.L. Baldochi, S.P. Morato, N.D. Vieira Jr., M.M.F. Vieira, Opt. Commun. 151, 366 (1998).

[63] M. Duarte, E. Martins, S.L. Baldochi, N.D. Vieira, Jr., M.M.F. Vieira, Opt. Commun. 159, 221 (1999).

[64] S.A. Payne, L.L. Chase, L. Smith, W.A. Kway, H.W. Newkirk, J. Appl. Phys. 66, 1051 (1989).

[65] S.A. Payne, L.L. Chase, H.W. Newkirk, L.L. Smith, W.F. Krupke, IEEE J. Quant. Electron. 24, 2243 (1988).

[66] J.J. DeYoreo, L.J. Atherton, D.H. Roberts, J. Cryst. Growth 113, 691 (1991).

[67] D. Klimm, P. Reiche, Cryst. Res. Technol. 33, 409 (1999).

[68] M.C.H.M. Ruiz, E.A. Barbosa, E.P. Maldonado, S.P. Morato, N.U. Wetter, N.D. Vieira Jr, S.L. Baldochi, J. Cryst. Growth 241, 177 (2002).

[69] A.M.E. Santo, S.L. Baldochi, S.P. Morato, J. Cryst Growth 198, 466 (1999).

[70] D. Klimm, G. Lacayo, P. Reiche, J. Cryst. Growth 210, 683 (2000).

[71] Handbook of Crystal Growth, Vol. 2, Ed. D.T.J. Hurle, North Holland, Amsterdam 1993.

[72] R.E. Samad, G.E.C. Nogueira, S.L. Baldochi, N.D. Vieira Jr., J. Opt. A, Pure Appl. Opt. 10, 104010 (2008).

[73] R.E. Samad, G.E.C. Nogueira, S.L. Baldochi, N.D. Vieira Jr., Appl. Opt. 45, 3356 (2006).

[74] R.E. Samad, G.E.C. Nogueira, S.L. Baldochi, N.D. Vieira Jr., Proc. SPIE 6101, 610112 (2006). 